Journal of Research in Interprofessional

Practice and

Education

Vol. 4.1

June, 2014
Journal of Research in Interprofessional Practice and Education (JRIPE)

Vol. 4.1

(C) 2014

Corresponding Author:

Clare MC Whitehead.

Email:icwhit009i'

!@uottawa.cạ!

\section{Harmonious Healthcare Teams: What Healthcare Professionals Can and Cannot Learn from Chamber Musicians}

\author{
Clare M.C. Whitehead, AB; Cynthia Whitehead, MD, PhD; \\ Gabrielle F.D. McLaughlin; Zubin Austin, BScPhm MBA, MISc, PhD
}

\begin{abstract}
Background: As healthcare becomes increasingly team based, we need new ways of educating trainees to be collaborative team members. One approach is to look to other professions that have developed highly effective ways of collaborating. Doctors have already turned to musicians for specific lessons; however, as of yet, there has been little empirical study of the ways that musicians interact in ensembles, or analysis of how this might provide insights for healthcare. Our hypothesis is that healthcare teams might learn from understanding collaborative practices of chamber musicians.
\end{abstract}

Methods and Findings: We undertook an exploratory study of professional musicians playing in non-conducted ensembles. We used semi-structured interviews to explore factors the musicians considered important for effective group function. The interviews were transcribed and coded thematically. We identified three prominent themes that have relevance for healthcare teams.

Conclusions: The highly individual nature of each musical group's identity suggests that a focus on generic interprofessional education skills development may be insufficient. Furthermore, musicians' understanding of the fundamental role of non-melodic parts provides the possibility of more nuanced leadership models. Finally, essential differences between musicians' interactions in rehearsals and performances highlight the importance of varied forms of group interactions.

Keywords: Interprofessional; Musician; Collaboration; Communication; Teamwork

\section{Introduction}

There is widespread recognition that changes are needed in health professions education to meet current patient and social healthcare needs $[1,2]$. Health systems are increasingly complex, aging populations and chronic disease management demand different care models, and preventable errors are costly and deadly [3]. Better collaboration between health professionals should help to solve many of these issues, yet healthcare teams are still struggling to develop effective models of collaboration, and health professions educators are continuing to explore optimal ways to teach learners to be ready for collaborative practice [4-7]. One potential way forward is to look outside healthcare to others who have found effective ways of learning to work together.

Music is one discipline that can provide medicine with insights. Lessons have already been drawn from music for specific aspects of health education. Kneebone, for example, examines the process of practice, rehearsal, and performance in music, and compares it to the practice and performance of surgical skills [8]. Kneebone argues that rehearsal-where the technical skill that had been mastered in isolation 
2

Harmonious

Healthcare Teams

Whitehead, Whitehead, McLaughlin, \& Austin

Journal of Research in Interprofessional Practice and Education

Vol. 4.1

June, 2014 is then practised in a context more relevant to the performance-is missing from healthcare models of skill development. By considering musical rehearsals, he proposes simulated environments for the rehearsal of surgical procedures [8]. Looking more generally at how musicians are trained, Davidoff argues that there are many additional lessons that doctors can learn: the necessity of teamwork, diligent and constant practice, investment of time into training, and creativity [9]. Others have used metaphorical associations to link health professionals (mostly doctors) and musicians. Physicians have been compared to jazz musicians [10], in terms of effective listening and learning to improvise $[11,12]$. Rock musicians are like physicians in that they are aware that their interactions with the audience are important and that each concert is the audience's first impression [13,14]. Reference has also been made to the fact that musicians most often perform in ensembles, so musicians in leaderless groups may be able to offer insights into how healthcare teams might function.

Much of the literature comparing musicians to health professionals has been speculative or reflective, with little empirical study of musicians. In particular, there has not yet been detailed research on the ways that musicians interact in ensembles and how this might provide insights into healthcare team function and health professions education curricula. Given the critical importance of improving healthcare team collaboration, we undertook a study of high-functioning, non-conducted small musical ensembles. The aim of this study was to better understand how collaborative musicians work together to see whether healthcare teams might be able to learn from them. By looking in-depth at factors these musicians consider important for effective group function, we were able to identify several key areas that are relevant for healthcare teams to consider.

\section{Methods}

For this exploratory study, we used standard qualitative methods [15] and conducted thematic analysis [16] of our findings. A semi-structured interview protocol was developed [17] and used to guide interviews with professional chamber musicians. Inclusion criteria for this study were: a) formal, university-based training in music performance and/or education and b) five or more years of actual performance experience as a paid musician in a chamber music ensemble consisting of at least three musicians. A professional chamber musician (GFDMcL) with previous academic experience in qualitative research methods conducted the interviews. Recruitment for this study was undertaken using snowballing techniques [18], building upon the professional networks of the interviewer and participants. All interviews were audio-taped and verbatim transcripts were produced. All transcripts were independently reviewed and coded by three reviewers (one experienced health professional and qualitative researcher (ZA), one professional musician $(\mathrm{GFDMcL})$ and one non-professional musician with extensive experience in chamber groups $(\mathrm{CMCW})$ ) to elicit themes; confirmation of themes was undertaken once independent coding was completed. Elaboration and contextualization of themes to focus on issues of relevance to healthcare teamwork 
3

Harmonious

Healthcare Teams

Whitehead, Whitehead, McLaughlin, \& Austin

Journal of Research in Interprofessional Practice and Education

Vol. 4.1

June, 2014 was then undertaken by an experienced healthcare professional with qualitative research expertise (CW). All participants provided informed consent pursuant to an ethics protocol approved by the University of Toronto Research Ethics Board. No compensation/remuneration was provided to participants.

\section{Results}

We anticipated that this study would provide models or lessons for health professions education. Yet, as we proceeded, we were somewhat surprised to find several important differences between musical ensembles and healthcare teams. We realized that a superficial application of the language of music to healthcare settings would be insufficient, due to the differences between the structures of medicine and music. However, through in-depth analysis of these musician interviews, we identified areas musicians consider key for effective ensemble work that are relevant for health care. These are: the individual nature of each musical group, the fundamental role of accompaniment, and the different group interactions that occur in rehearsal and performance.

\section{Musical Parts}

In a small musical ensemble, each member plays a different part, and often, a different instrument. For example, in a string quartet, there are two violinists, a violist, and a cellist. Each musician has a clearly defined musical part-the music is in front of them and their job is to play the notes that are written on the page. An initial comparison of how chamber musical groups function to how healthcare teams might improve could lead to the conclusion that musical groups work effectively because each person has a clearly defined part, and healthcare teams should therefore learn to lay out the roles of each member involved in an explicit manner. In the literature on healthcare team function, there is significant attention paid to the importance of understanding the roles and scopes of team members [19]. However, when we studied what musicians say about the members of their groups, we found that the individual members are very important in determining how the group will work, that it is not easy to replace one player with another who plays the same instrument, and that there is no prescribed formula for how members of an ensemble will work effectively together.

Musical groups have an individual identity and group culture. Each group establishes its own way of working together, resolving conflicts, and developing musical interpretation, based on the people involved. As interviewee 12 noted, "the route to finding an ensemble which works well together is different every time." The personalities of group members play a big role in determining how the ensemble will function, and when it will not function. In groups that work well together, musicians express satisfaction in being able to work effectively with the other personalities in the group (see Table 1,\#1). While it is important that the members be compatible musically, it is also essential that they are able to get along as people (see Table 1,\#2). Incompatible personalities can lead to conflicts resulting in some members leaving the group (see Table 1, \#3). 
4

Harmonious

Healthcare Teams

Whitehead, Whitehead, McLaughlin, \& Austin

Journal of Research in Interprofessional Practice and Education

Vol. 4.1

June, 2014
Because of the importance of personalities meshing in a group, it is not possible to replace one musician with another of equal musical ability who plays the same instrument. Instead, new members are chosen with care, and are added to the group based on not only musical proficiency but also personal compatibility. Musicians emphasize the importance of carefully selecting new members; for example, many ensembles have auditions for new members in which the candidates rehearse with the established ensemble.

In addition, new members of an established group describe the process of joining the group as challenging. They explain that it takes time to understand how the group works and the traditions that have been established over years (see Table 1, \#4). In the initial period, new members describe the importance of accepting that they will not intimately understand the group interpretation of a piece, aspects of the rehearsal process, or all the discussions among the other members (see Table 1, \#5).

\section{Implications for health professions education}

Healthcare teams are rarely chosen with the same care that goes into creating musical ensembles. Employment standards and union requirements can limit healthcare teams' ability to choose or change members. Even when healthcare teams participate in interviewing potential new members, personalities are not generally given great priority. Patient needs and system pressures combine with expectations of professionalism [20] so that the personal level of interaction on healthcare teams is rarely openly discussed or considered. Moreover, many healthcare teams are in regular flux, with nurses coming and going on shifts and physicians rotating on and off service [21]. If healthcare teams do not have the option of adopting the approach to member selection so highly valued by chamber musicians, we must consider what limitations this imposes on the nature of team performance and types of team interaction that can be hoped for.

One finding that healthcare teams might take from chamber musicians is their understanding that each group is different, and that being a good member of one team will not necessarily translate into being a good member of a different team. Hence, we may need to be somewhat cautious about current enthusiasm for generic "group skills training" that permeates many of the models of interprofessional education (IPE) [22].

\section{Melody and Accompaniment}

In some forms of music, one instrument plays the melody at a given time, while the others provide accompaniment. The instrument playing the melody can change, and the melody is passed between instruments during a piece. After leaving a concert hall, members of the audience will often be left humming parts of the melody, or tune, of the pieces they just heard performed. Considering the idea of melody and accompaniment, it may appear that the melody is the most important part and that those playing the supporting lines must follow. Drawing lessons for healthcare teams from this idea, one might conclude that healthcare providers should be constantly listening for who has the melody, and have the flexibility to allow another 
5

Harmonious Healthcare Teams

Whitehead, Whitehead, McLaughlin, \& Austin

Journal of Research in Interprofessional Practice and Education

Vol. 4.1

June, 2014 part to come forward when it has the melody. However, we found that musicians emphasize that the accompaniment is essential for the group sound, and that those playing supporting parts have an important and very interesting role to play in creating the music.

In chamber ensembles, each instrument has a different, yet vitally important contribution to make to the group sound; the parts are not equal (see Table 2, \#1), yet musicians emphasize the importance of all of the parts. Ensemble members playing supporting parts take great pride in the ways they are able to support the melody, and melodic players emphasize the importance of accompanists with a good understanding of the entire piece (see Table 2,\#2). Allowing the inner voices of a piece occasional dominance helps to create a balanced, vertical sound, rather than a horizontal, "melody-based" sound (see Table 2, \#3). Given that the appropriate balance is not always clear at any particular time, musicians must develop an awareness of when their parts need to come through and when they should follow another part; they must constantly be listening to understand how their parts fit into the sound that is being created (see Table 2, \#4). Despite the necessity of having some musical lines be more prominent than others at certain times, this does not mean that certain members have a more prominent voice in rehearsals than others (see Table 2, \#5). All members must have confidence and a strong personality (see Table 2, \#6), but also be responsive to criticism from all other group members (see Table 2, \#7). Ensemble players warn that difficulties can arise when musicians are not self-aware or consider their parts to be the most important (see Table 2, \#8). Chamber musicians are aware that they are working with other people and that they must change and adapt based on the personalities of the individual members of the group (see Table 2, \#9).

\section{Implications for health professions education}

On healthcare teams, interactions are often framed in terms of team leadership $[23,24]$. Physicians frequently play leadership roles; however, shared leadership models are increasingly considered in interprofessional education contexts [19]. The traditional use of hierarchical leadership models is perhaps not surprising, given that team members have different backgrounds, training, salaries, employment reporting relationships, and levels of status and authority. These are not factors that can or should be ignored. However, by framing interactions in terms of team "leaders," others by implication become "followers" and are therefore placed in a passive role. With this framing, healthcare teams may be missing out on a different way to conceptualize interactions. Musicians' strong appreciation of balance and the need for all members to be active participants and forceful voices may be useful for healthcare teams. As the twentieth century Russian composer Dmitri Shostakovich pointed out (using the analogy of characters in a play):

If only the hero speaks and the others don't reply, the play becomes nonsense and boring. All the characters must speak, so that we hear the question and the answer, and then following the course of the play's action becomes interesting. [25, p. 96] 
6

Harmonious Healthcare Teams

Whitehead, Whitehead, McLaughlin, \& Austin

Journal of Research in Interprofessional Practice and Education

Vol. 4.1

June, 2014
The findings from chamber musicians provide an opportunity for healthcare teams to think about alternate ways to value and recognize the supporting roles played by certain team members. Chamber musicians who generally play inner parts know the importance of their contribution to the music and do not hesitate to speak up forcefully in rehearsals. Musicians acknowledge that there are differences among all the parts, but emphasize each in its turn. Health professions educators may be able to create more nuanced models of interaction by drawing upon these ideas.

\section{Rehearsal and Performance}

To get to a concert stage, a musical group must first put in hours of individual practice, where the members learn how to play their parts, followed by many rehearsals, where the group learns to play the pieces together. It is as a result of the process of practice and rehearsal that the group is able to perform. Comparing music to medicine, this suggests that healthcare teams should practise individually and then rehearse together before they may skilfully perform a procedure. This idea has been used as a way to improve specific skill development, such as the technical skills of surgeons [8]. However, when considering team interactions, the relationship between rehearsal and performance requires analysis from a different perspective. Musicians emphasize the difference between rehearsal and performance as much more than simply mastering a piece before presenting it to an audience. For a chamber group, rehearsal and performance represent two distinct ways in which the group must work together, both of which are essential for the development of the ensemble as a whole.

During the rehearsal process, members of the ensemble contribute ideas about the piece and different options are tried. Musicians emphasize that it is important that they feel their ideas are valued and respected by their colleagues and that they themselves have an appreciation for the suggestions and criticisms raised by others (see Table 3,\#1). The rehearsal is a time to try all ideas, and it is important that all members have the opportunity to voice opinions, and feel welcome to do so (see Table 3, \#2). A high level of respect must be maintained, but effective rehearsals can involve arguments among the musicians-as long as the discussion remains focused on the music (see Table 3, \#3). While rehearsal styles vary among groups, it is clear that the process of developing ideas with the input of all group members is important for effective group function in chamber ensembles.

Unlike rehearsal, in a performance the group comes together to present one unified idea and the members support each other through any difficulties that arise. A performance is not a time to fight or to prove a point (see Table 3, \#4). Concerts do not always go perfectly, and when things start to go wrong, musicians rely on their colleagues to help the group recover (see Table 3, \#5). Once a performance starts, the group cannot stop, no matter how difficult things get (see Table 3, \#6). Many musicians comment that when something goes wrong during a performance, it is best to shake it off and continue. A concert is not an appropriate time to criticize personal errors or to worry that other members may be disappointed (see Table 3, 
7

Harmonious

Healthcare Teams

Whitehead, Whitehead, McLaughlin, \& Austin

Journal of Research in Interprofessional Practice and Education

Vol. 4.1

June, 2014
\#7). In fact, several musicians explain that they play better when they have the freedom to take risks during a performance, since they know that their colleagues will support them and understand if it does not succeed (see Table 3, \#8).

Musical groups rely on the combination of rehearsals and performances to develop as a group. They are two distinct processes (see Table 3,\#9), yet both are essential for developing a group trust, which only happens with time (see Table 3 , \#10).

\section{Implications for health professions education}

On many healthcare teams, most interactions relate directly to patient care, so the musical constructs of rehearsal and performance cannot be fitted neatly into healthcare team processes. And while the term performance is used frequently in healthcare, its use is not identical to musicians' notion of performing, particularly as differentiated from the music ensemble rehearsal process. We need to be careful to avoid importing terms directly from other settings (such as music) in a literal way, as this may lead to over-simplification of complex processes. A detailed analysis of chamber musicians' ideas can nevertheless provide useful analogies for healthcare. In considering rehearsal and performance, the importance chamber groups place on different types of interactions at different times may provide healthcare teams with novel and innovative ways to think about their own interactions. For chamber musicians, rehearsals are a place to question, argue, and try out different approaches, whereas performances are a place to pull together and support each other. Healthcare teams may benefit from considering how each of these important forms of group interaction can occur in the context of their own teams. Team rounds and team meetings are not "rehearsals" for an upcoming performance. However, team rounds or meetings might be one place to consider incorporating the types of critical and reflective group discussions that musicians realize are essential to good group function. Teams also need to acknowledge that there are occasions where the focus must be on supportive teamwork. If healthcare teams can find a way, within their practices and processes, to engage in both of these distinct types of interaction, this may lead to more effective team function. Similarly, health professions educators may be able to develop more nuanced models of interactivity for interprofessional education programs by building upon these findings.

\section{Discussion}

Working well as a team in the complex health systems of the twenty-first century is essential. It is, however, more difficult to develop collaborative practice and education models than it might first appear. Looking at other areas in which high functioning professionals work together effectively may provide useful insights for healthcare.

There is a charm to the idea that healthcare teams can perform like musical groups. Sitting in the audience, listening to a chamber ensemble, there is a sense of wonder at how effectively the members work together to produce beautiful music. It is appealing to think that other teams might be able to model their work on musical ensembles. Yet in order to gain relevant insights about teamwork and collabora- 
8

Harmonious

Healthcare Teams

Whitehead, Whitehead, McLaughlin, \& Austin

Journal of Research in Interprofessional Practice and Education

Vol. 4.1

June, 2014 tion, we must understand the work that musicians put in and the difficulties that they face. Just as any other team, a chamber ensemble struggles to develop effective collaboration. It is a challenging process to reach a performance where a high level of trust is achieved. Ensembles struggle to accept criticism from peers during rehearsals, accommodate the forceful personalities of the group, and develop an understanding of how their group will function. Yet musicians know that this work is essential in order to achieve an effective performance. By examining in detail the ways in which musicians work through acknowledged challenges and reflect on the collaborative process, it becomes possible to draw meaningful connections to comparable difficulties faced by healthcare teams.

In comparing musicians and healthcare providers, it is important not simply to apply the language of music to the practice of medicine. Given the differences in structures of the two systems, constructs that work effectively in music may not at first appear to be relevant to healthcare. For example, the part each musician plays in a chamber group is defined by the sheet music; the distinctions between the instruments and the ideas of rehearsal and performance do not easily fit healthcare settings. However, in considering how musicians think about these different processes, we begin to see intriguing connections. Through musicians' emphasis on the individual personalities of group members, the limitations of having a more rigid structure for selecting healthcare team members can be considered. The importance musicians place on accompaniment and inner parts shows the possibility of a more nuanced model of interaction than a traditional leader and follower hierarchy. Finally, the value of having different contexts of group interaction, with times for critical argumentation as well as unified support, demonstrates the potential for new and distinct types of team interaction in healthcare.

The major limitation of this study is that it is preliminary and exploratory, and many of the comparisons to healthcare teams were speculative in nature. This is unavoidable as it is a first attempt to gather empirical data about chamber music collaboration relevant for healthcare team collaboration. It does not, therefore, allow for generalizability. It does, however, suggest innovative possibilities for healthcare teams, providing exciting areas for future research.

As healthcare teams search for new models of collaborative practice and education, it is important to acknowledge that teamwork is not easy and that development of highly functioning groups requires hard work. However, by examining the ways in which other groups, in this case chamber music ensembles, have worked through challenges, it may be possible to investigate better models of collaboration. This study provides some preliminary insights. More in-depth research analyzing ways in which musicians work together could provide more specific approaches for effective collaboration in healthcare teams and improved interprofessional education curricula. By moving beyond romantic notions of healthcare providers as rock stars or classical virtuosos, healthcare teams may be able to incorporate some of the creativity of interaction that allows chamber music ensembles to flourish. 
9

Harmonious

Healthcare Teams

Whitehead,

Whitehead,

McLaughlin,

\& Austin
Journal of Research in Interprofessional Practice and Education

Vol. 4.1

June, 2014

\section{References}

1. World Health Organization. (2010). Framework for action on interprofessional education \& collaborative practice. Report No.: WHO/HRH/HPN/10.3.

2. Frenk, J., Chen, L., Bhutta, Z.A., Cohen, J., Crisp, N. et al. (2010). Health professionals for a new century: Transforming education to strengthen health systems in an interdependent world. Lancet, 376(9756), 1923-1958.

3. Institute of Medicine. (2002). The future of the public's health in the 21st century. Washington, D.C.: National Academy Press.

4. Carpenter, J., \& Dickinson C. (2011). Contact is not enough: A social psychological perspective on interprofessional education. In Kitto, S., Chesters, J., Thistlewaite, J., \& Reeves, S. (Eds.), Sociology of interprofessional health care practice: Critical reflections and concrete solutions. New York: Nova Science Publishers.

5. Lemieux-Charles, L., \& McGuire, W.L. (2006). What do we know about health care team effectiveness? A review of the literature. Medical Care Research and Review, 63(3), 263-300.

6. McCulloch, P., Rathbone, J., \& Catchpole, K. (2011). Interventions to improve teamwork and communications among healthcare staff. British Journal of Surgery, 98, 469-479.

7. Reeves, S., Zwarenstein, M., Goldman, J., Barr, H., Freeth, D. et al. (2008). Interprofessional education: Effects on professional practice and health care outcomes. Cochrane Database Systematic Review, Issue 1. Art. No.: CD002213.

8. Kneebone, R.L. (2009). Practice, rehearsal, and performance: An approach for simulation-based surgical and procedure training. Journal of the American Medical Association, 302(12), 1336-1338.

9. Davidoff, F. (2011). Music lessons: What musicians can teach doctors (and other health professionals). Annals of Internal Medicine, 154, 426-429.

10. Smith__R_(2004)._Doctors_are _not scientists._British_Medical Journal, 328(7454), n.p. URL: thttp://wwww.ncbi.nlm.nih.gov/pmc/articles/PMC428500![Ostober_7,_2012]

11. Hentoff N (2009) How jazz can help doctors listen. URL ihttp:/jazztimes com/articles/24523. 'how-jazz-helps-doctors-listenn'; [October 7, 2012].

12. Moyer _C.S_ (2010) Iazz offers lessons_for doctor-patient interaction. URL: 'htttp://www.ama-assn' torg/amednews/2010/05/17/prse0517/htm [O_tober Z 2012].

13. Wood 12012 Rock ster doctors 'doctors-what-physicians-can-learn-from-musicians/:'[October 7, 2012].

14. Dimov,_V._(2012). What_musicians san_teach dostors, and how allergists_are_like rock stars. URL:

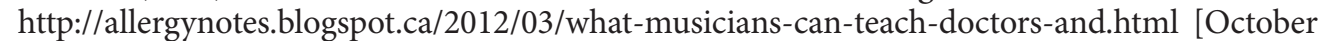
7, 2012].

15. Kuzel, A.J. (1999). Sampling in qualitative inquiry. In Crabtree, B.F., \& Miller, W.L. (Eds.), Doing qualitative research, 2nd edition. (pp. 33-45). Thousand Oaks, CA: Sage Publications.

16. Denzin, N.K., \& Lincoln, Y.S. (2005). Introduction: The discipline and practice of qualitative research. In Denzin, N.K., \& Lincoln, Y.S. (Eds), The SAGE Handbook of Qualitative Research, 3rd edition. (pp. 1-32). Thousand Oaks, CA: Sage Publications.

17. Kvale, S. (1996). InterViews. Thousand Oaks, CA: Sage Publications.

18. Patton, M.Q. (1990). Qualitative evaluation and research methods. Newbury Park, CA: Sage Publications.

19. Barr, H., Koppel, I., Reeves, S., Hammick, M., \& Freeth, D. (2005). Effective interprofessional education: Assumption, argument and evidence. London: Blackwells.

20. Stark, S., Stronach, I., \& Warne, T. (2002). Teamwork in mental health: Rhetoric and reality. Journal of Psychiatric and Mental Health Nursing, 9(4), 411-418.

21. Chesters, J., \& Burley, M. (2011). Beyond professional conflict: Cultural and structural barriers to interprofessional health care teams. In Kitto, S., Chesters, J., Thistlewaite, J., \& Reeves, S. (Eds), Sociology of interprofessional health care practice. (pp. 105-118). New York: Nova Science Publishers.

22. Oandasan, I., \& Reeves, S. (2005). Key elements of interprofessional education. Part 2: Factors, processes and outcomes. Journal of Interprofessional Care, 19(s1), 39-48.

23. Allen D. (1997). The nursing-medical boundary: A negotiated order? Sociology of Health and Illness, 19(4), 498-520.

24. Hall P., \& Weaver L. (2001). Interdisciplinary education and teamwork: A long and winding road. Medical Education, 35(9), 867-75.

25. Steinhardt, A. (1998). Indivisible by four. New York: Farrar Straus Giroux. 
10

Harmonious Healthcare Teams

Whitehead, Whitehead, McLaughlin, \& Austin
Journal of Research in Interprofessional

Practice and

Education

Vol. 4.1

June, 2014
Table 1

\section{Musical parts quotations (numbers in bold indicate the interview number from which the quotation is taken)}

1 11: "And we also happened to work in the same way, which, even though we came from different teaching styles, was extremely important. We would recognize the same things that we needed to work on. ... constantly saying 'Let's fix this, fix, this, fix this' until we got to a point where we all were happy with what we were producing."

13: "In spite of the fact that B is quite a bit younger than us, we all get along both socially and musically extremely well."

8: "The personalities have to mesh well. ... I think the best ensemble is one where there is a nice mixture of personality elements."

2 9: "I guess when it's unrewarding it is either that there's some kind of psychological shit going on somehow or that you've gotten yourself into a situation where somebody, on a musical level, just can't do what they said they could do."

4: "The relationship that we have is not just business. It is based in friendship as well. ... The friendship evolved out of the musical/business relationship."

3 6: "She had a way of just constantly drawing attention to herself in a way that drew away from the music. That was her style. She was very dramatic and very funny. Very entertaining person, but this high-maintenance side."

7: "We had a bass who was always making problems out of not-problems ... He was not happy and he would take time to make everyone unhappy too. ... He never fit the group and he wanted people to pay attention to him a lot. He wanted to be the most serious and the most historical and the most, I don't know, like a soloist. He also had nobody around who was really like a friend. We are all friends in our group ... we did not purposely exclude him, but no one was really his friend. ... He was angry at everyone because he was not happy with himself and because his technique was not strong."

4 1: "I think that it takes time for somebody coming into it to comprehend the group values and the group dynamic and the group approach to things. ... [It] took me time to figure out where, I mean to put it a crude-ish way, but where the bodies were buried. What things you don't talk about, and what events have shaped the group, what kind of topics are available, and what kinds of topics aren't available, and I think sometimes with the groups that we found we're not aware of the questions that aren't asked."

12: "If you join a group which is already established ... you have to actually somehow learn to fit into the established routine. ... The established routine is that if you know somebody for a long time, a lot of things are said without saying them. A lot of habits are created which either help or hinder your relationship. Hopefully they help your relationship, and if you're not aware of what those are or you weren't a part of their formation, then you have to be sensitive to the fact that probably there are things you don't understand."

$5 \quad$ 3: "I think for me one of the biggest challenges is the moments where you know that something's going on and you know that you don't know what it is and you know that you can't ask what it is."

3: The "process of kind of waiting it out and knowing that at some point I'm going to know what just went on there, but it's not going to be right now."

12: "So they want very much that it's going to work. Plus, they want their quartet to continue, so there are many levels at which they want to make it work. Initially, the relationship is an easy one ... My first year was to sit and listen, and there were times when I thought about the interpretive differences, but at a certain point I realized that it was fruitless and counterproductive and it became essential for me, if I wanted to stay in the group and make it function as a quartet, that I simply adopt much of what they had established because they were, after all, Ensemble 2, and I was an outsider." 
11

Harmonious

Healthcare Teams

Whitehead, Whitehead, McLaughlin, \& Austin
Journal of Research in Interprofessional

Practice and

Education

Vol. 4.1

June, 2014
1 11: "And we also happened to work in the same way, which, even though we came from different teaching styles, was extremely important. We would recognize the same things that we needed to work on. ... constantly saying 'Let's fix this, fix, this, fix this' until we got to a point where we all were happy with what we were producing."

13: "In spite of the fact that B is quite a bit younger than us, we all get along both socially and musically extremely well."

8: "The personalities have to mesh well. ... I think the best ensemble is one where there is a nice mixture of personality elements."

2 9: "I guess when it's unrewarding it is either that there's some kind of psychological shit going on somehow or that you've gotten yourself into a situation where somebody, on a musical level, just can't do what they said they could do."

4: "The relationship that we have is not just business. It is based in friendship as well. ... The friendship evolved out of the musical/business relationship."

3 6: "She had a way of just constantly drawing attention to herself in a way that drew away from the music. That was her style. She was very dramatic and very funny. Very entertaining person, but this high-maintenance side."

7: "We had a bass who was always making problems out of not-problems ... He was not happy and he would take time to make everyone unhappy too. ... He never fit the group and he wanted people to pay attention to him a lot. He wanted to be the most serious and the most historical and the most, I don't know, like a soloist. He also had nobody around who was really like a friend. We are all friends in our group ... we did not purposely exclude him, but no one was really his friend. ... He was angry at everyone because he was not happy with himself and because his technique was not strong."

$4 \quad$ 1: "I think that it takes time for somebody coming into it to comprehend the group values and the group dynamic and the group approach to things. ... [It] took me time to figure out where, I mean to put it a crude-ish way, but where the bodies were buried. What things you don't talk about, and what events have shaped the group, what kind of topics are available, and what kinds of topics aren't available, and I think sometimes with the groups that we found we're not aware of the questions that aren't asked."

12: "If you join a group which is already established ... you have to actually somehow learn to fit into the established routine. ... The established routine is that if you know somebody for a long time, a lot of things are said without saying them. A lot of habits are created which either help or hinder your relationship. Hopefully they help your relationship, and if you're not aware of what those are or you weren't a part of their formation, then you have to be sensitive to the fact that probably there are things you don't understand."

$5 \quad$ 3: "I think for me one of the biggest challenges is the moments where you know that something's going on and you know that you don't know what it is and you know that you can't ask what it is."

3: The "process of kind of waiting it out and knowing that at some point l'm going to know what just went on there, but it's not going to be right now."

12: "So they want very much that it's going to work. Plus, they want their quartet to continue, so there are many levels at which they want to make it work. Initially, the relationship is an easy one ... My first year was to sit and listen, and there were times when I thought about the interpretive differences, but at a certain point I realized that it was fruitless and counterproductive and it became essential for me, if I wanted to stay in the group and make it function as a quartet, that I simply adopt much of what they had established because they were, after all, Ensemble 2, and I was an outsider." 
Harmonious Healthcare Teams

Whitehead, Whitehead, McLaughlin, \& Austin
Journal of Research in Interprofessional Practice and Education

Vol. 4.1

June, 2014
Table 2

\section{Melody and accompaniment quotations (numbers in bold indicate the interview number from which the quotation is taken)}

1 6: "It's something that, when you play in a group such as ours, you can't not acknowledge that the pianist has a bazillion notes and that we just have a single line usually, and I don't think a reasonable pianist is willing to stand by that whole argument to the death—-that their job is harder."

2 1: "I think that there are a lot of secret and insidious ways that inner voices can direct things. ... Mostly I feel like when things are going well, we're all on one side of the rock pushing one way. So what I do with my little supporting role is a part and parcel of what the whole operation is. ... I feel like when it's going well, mostly we're all in sync. And there are occasional moments when you've got to make an adjustment here and there, and I think being understanding and forgiving goes a long way."

8: "Continuo playing tends to attract people like me who like to be in a supporting role ... they feel comfortable helping [the soloist] sound good."

9: When you have a scary passage in a solo part, "in the course of the performance, and when you start rehearsing, when you get to the scary bits, listen to the continuo. So, yes, you're playing this, you're doing this, but you're listening. ... attention paid to how the whole thing sounds and almost putting yourself in the role of the person who is accompanying you deflects fear of what it is that you're actually doing."

10: "The best accompanists in the world are the people who know what I'm doing."

11: "I think the general tendency is to assume that the melodic line or the most prominent line is the one at the top. But I think the truth is that it needs the support of what on the bottom. Again, the concept of the weakest link. I think it's extremely important that the basis is there. So I don't mean just bass in terms of music, but the accompanying material is really solid, because that's what lets the melodic line really soar and really sing, and if it's not strong, you can have the most phenomenal melodic player in the world — they're not going to sound great."

3 11: "All the voices need to be heard, regardless of who's dominant. And when they're all heard in the right kind of balance the music makes sense."

11: "I think what makes music really interesting is when any one of those people who's doing something that might not necessarily be considered dominant voice or melodic voice just pushes it a little and says 'Hey, hello, look! I'm here! Listen to me!' That just promotes an awareness in everyone else's ear."

10: "What I love about Baroque music is that there's always an obligato line and it's always driven by the continuo line. So you can't have a passive continuo player, and that's what I really like - the polarities and the kind of ferocious personalities that have to exist at each side of that. And then how important the inner voices are. [laughs] You have to set up all the time and not every setting allows for that, but when the music sounds good to me, that's when people are allowed to step up."

$4 \quad$ 8: "Often guitarists and keyboard people don't get as much chamber music experience because we're basically busy learning solos - especially in the guitar world ... And that's the reason why a lot of guitarists don't collaborate well on a ... not so much on a personal level but just in terms of instincts. Being aware of who's in control of the beat at any given place in a piece of music and things like that."

9: Playing a non-solo part: "You just listen. It's an understanding of what's going on in the music."

9: "People who do follow, they just follow. And you need to know when you're in the driver's seat and when you're in the passenger's seat."

9: "And when I'm working with singers, again I find it useful because if it's the obligato part of a Bach cantata or aria, I like to see, when I hear the singer doing the same melodic pattern, and I'm paying attention to what words they have because it will also help shape the phrasing, and I like the weaving in and out, and I just try and look at it as also some kind of a puzzle or some kind of a pattern that you are doing this weaving. And it works best that way because if everybody is thinking along the same lines is when it works the best." 
13

Harmonious

Healthcare Teams

Whitehead, Whitehead, McLaughlin, \& Austin
Journal of Research in Interprofessional

Practice and

Education

Vol. 4.1

June, 2014
11: "There has to be a certain awareness of what everyone is doing."

12: "I think the viola is quite a fascinating place to be. You have to learn when to say nothing and when to say a lot. But you can never allow a vacuum to be created, otherwise a violinist or a cellist might fall in. ... I like to think that a great violist can make a quartet sound fantastic just by virtue of the fact that he's sensitive to what kind of support each of the other three parts needs."

5 13: "I'd say we're fully democratic in how musical decisions get made, regardless of what role you're playing. They're all equally important roles, naturally."

6 6: "If you're insecure in what you do in any way, you do not make a good collaborator."

10: The leader is not actually the driving force behind everything: "The leader exists only because he's supported."

10: "The best collaborative groups are made up of the most independent minds, and that's what works for me. If people are passive then they inevitably get angry, and that's useless. That kind of simmering anger. Explosive anger's useful, but simmering, long-term resentful anger is absolutely useless."

7 13: "I don't feel that there are lingering resentments. Everybody has a similar kind of approach that everybody really loves the music; I feel that everybody is not very highly ego-invested and is open when somebody says: 'You're sharp', or 'You're flat,' or whatever. And doesn't get defensive, generally."

13: "Really important that people [are] ... open to be able to give criticism and accept criticisms in a way that is not criticizing the person but simply pointing out something to work on and something that the group wants to achieve and not being critical of the person themselves. And being able to accept criticism in that spirit."

8 6: "As soon as you get somebody who feels that their part is the most important part or plays the central role, then they give themselves the right to always reference everybody else's contribution to their own. And it just doesn't let them give as much. I think in every situation there is more than one way to make it through the hurdles, and I think well-educated, confident, experienced people make good collaborators."

9: "People for whom they are the end ... you immediately get into this issue about you versus me as opposed to 'let's transcend the you versus me and let's see what we can make."'

9: "One [factor] is that the people in an ensemble are always interested in how they work themselves. What makes them tick. And they are aware of their foibles as well as their strong points. ... But it's something about self awareness that if everybody in the group has some kind of ... they're also aware of what that brings to the mix."

11: "But I think it's when people aren't willing to look at themselves and their own weakness - not weakness but fallibility [that it's challenging]."

13: "Really important that people not be narcissistic or heavily focussed on themselves and that they be able to step back pretty effectively from their own issues and be able to accept the feelings of everybody else."

9 7: "There is no way everyone can just fit into a little box that is made by, I don't know, Mattel, and work in perfect synchrony like a doll. We are all people, and sometimes people have to adjust to other people. Maybe because I have been adjusting to people for my whole life - my whole life I have needed people, and those people are not machines. And neither am I-I am not a machine. So we change our ideas and go with the flow of what is happening."

9: "And then also artistically, if people can bring different things to the mix and everybody is, have different goals in terms of how they might want to do something but a similar end goal." 
Harmonious Healthcare Teams

Whitehead, Whitehead, McLaughlin, \& Austin
Journal of Research in Interprofessional

Practice and

Education

Vol. 4.1

June, 2014
Table 3

\section{Rehearsal and performance quotations (numbers in bold indicate the interview number from which the quotation is taken)}

$1 \quad$ 1: "I can remember a moment when I made a suggestion, a musical suggestion, about something, and I remember the look on a couple different people's faces that I felt like at the moment I was unambiguously being taken seriously as a member of the ensemble."

9: "I need creative people, I need people who I admire for what they're willing to risk, what they're willing to try out, and I guess who I feel like I don't feel threatened by, who I also feel inspired by, and who I feel is not going to step all over me. ... if I've had a feeling in working with somebody that I don't really feel seen or appreciated by them, I'm less likely to want to collaborate."

11: "So if each person in the ensemble is strong and respectful of other members in the ensemble, I think that's key, then the group itself will become stronger."

12: "You have to know that what is being suggested is coming from somewhere that you believe in and that you trust and that you think has validity."

13: "If an atmosphere is created where everybody feels basically accepted and appreciated and respected and trusted, then I think each person from the atmosphere feels freer to let that [their ego] go."

2 4: "It's actually three people in the band, and we talk about things openly. Something is suggested and it's almost like an unsaid vote. People voice an opinion and it's two against one. It's really ... we try everything. There is definitely an openness to trying every idea that might be happening in that fleshing out stage, but there is no one person that has the final say."

9: "All of us get together, we all sit in a circle, everybody has a chance, nobody butts in, and nobody tells anybody else what's what. And a compromise gets reached, even if, at the outset, there can be a strong disagreement about something. And it's just because it's a question of processing through shit."

10: "Independence of mind and freedom of speech. It doesn't mean that people are going to say whatever the hell they think, it just means that there is a forum to speak up."

12: "Everybody will have suggestions, and those suggestions will be tried and they'll succeed or they'll fail. Sometimes the suggestions are good but they'll fail because the group itself does not function in such a way that it works."

13: "I feel really fortunate because the group works extremely well because we're really well matched. There's a very, very high level of trust in the group and communication is very good; when difficulties arise we feel that we can talk them over in an atmosphere of trust so we can solve them pretty easily."

3 1: "When the topic of the working conversation is the music, that's healthy. It doesn't mean you've got to get along. It doesn't mean you've got to agree about everything, but when you're still talking about the music, you're doing fine. ... you can be having a knock-down drag-out fight about whether this pick-up note is long or short or whatever, that's fine, go for it. Knock yourselves out. Still talking about the music. 1: "If we're talking about music, even if we're fighting about it, then I think we're succeeding."

10: "If people are passive then they inevitably get angry, and that's useless. That kind of simmering anger. Explosive anger's useful, but simmering, long-term resentful anger is absolutely useless."

$4 \quad$ 2: "When we're on stage we never will fight, we will always try to play the best we can."

2: "We had that with a French conductor who deliberately tried to sabotage the concert just to make a point of personalities, and that's very frustrating because there's nothing you can do. ... A concert is never a place to teach someone a lesson."

3: "It was one thing to be difficult in rehearsal and to be insistent and to be a bit of a bully about how you want things to be, but then to sabotage a concert was just ... You have to have a certain level of trust with people you're going to play a concert with, and the basics is that everyone is going to try and make the concert go as well as possible. ... I did play a concert after that with this same person in a similar capacity where he was leading from the harpsichord and I just had no trust at all that he wouldn't just make things sound bad." 
15

Harmonious Healthcare Teams

Whitehead, Whitehead, McLaughlin, \& Austin
Journal of Research in Interprofessional

Practice and

Education
4: "I remember feeling a breakdown on stage in a performance setting, where it was all of a sudden not the three of us against the audience — something was happening with myself against one of them. ... there was something that was communicated between someone else in the band and the audience that was completely violating the trust that you have with the people that you're on stage with. Which I think sort of needs to be there."

5 1: "I have come to, in a way, trust my colleagues more in the sense that it's not necessarily something that they are going to do, per se, but trust them to be supportive of me even when I do slip."

6 6: "We know that the conditions aren't right, we sort of know that there are things that each of us are doing that's not really making the others happy, and yet we still have to deal with what we consider to be a life and death situation. And that's a performance. For us, as performers, that's what it is. Once that starts, as you know, no stopping, no-you have a responsibility. You're on stage and you have to pretend that everything is fine. Audience doesn't care, doesn't know anything about these things, don't need to know about it." 12: When you don't have enough time to rehearse, "hopefully you're relying on the sense that if you get into trouble, somebody else on the stage will realize that because they're listening and they'll go in the right place at the right time to pull you out of the fire."

$7 \quad$ 1: "In the moment of performance is not the time to be revisiting that particular shortcoming or what might have happened because you've got a job to do."

6: "Sometimes we come away from these particularly challenging situations thinking: 'Well, not exactly a day that I'd feel that I've made the best music in the world, but it was much more like as a team, we climbed this Everest', and we just kind of laugh it off and keep moving."'

7: "My teacher at Longy gave me a lot of advice and told me a lot of things that have helped me over the years, and she always said that it is not good to look, to think about your concert after it is finished. Finished is finished, and you cannot change it. Not every concert or performance is going to be on a $C D$, and you can't think about it after it is finished."

8 13: "One thing is you trust them to be sane no matter how stressful things get. ... And you know that they can trust you to be there for them when they take risks."

11: "If I were playing in a group where I knew that I was respected musically by my colleagues, even if in performance I happened to do something that musically doesn't work—-because that's my style to try something different in performance - I would hope that the people I'm with would recognize that I was trying something and maybe it didn't work and they can all just laugh at it and say: 'Well, guess what, that didn't work, but hey, you tried it."'

$9 \quad$ 1: "My old teacher used to say: 'rehearsals are the war and the performance is the truce.' Fight all you want in rehearsal, but when it comes time to do it in public you've got to get along."

10 10: "Everything can't be a crisis. Rehearsals can't always be one day before the show. There have to be developmental periods where there is time to brainstorm."

11: "You're listening for that wonderful thing called 'concert' - that you're 'in concert' with each other in the same place. ... Because that helps you feel secure. Helps them feel secure." It only happens when people are either really familiar with the music (e.g., Eine kleine Nachtmusick), but "otherwise no, I think it has to happen when people have worked together for a long time. And there's trust-you trust the people you're working with. That's what it's about." Trust is "gained over time, it's gained over the rehearsal period. It's part of that mutual respect."

13: "It's just so much like being on a boat where you're all intimately depending on each little action of everybody else."

Vol. 4.1

June, 2014 
Harmonious

Healthcare Teams

Whitehead, Whitehead, McLaughlin, \& Austin

Journal of Research in Interprofessional Practice and Education

\section{Appendix \\ Semi-structured interview protocol: What can healthcare teams learn about collaboration from musical ensembles?}

Notes for Research Assistant:

- Introduce self and purpose of study.

- Ensure potential participant has read, reviewed, and understood Informed Consent document.

- Ask potential participant if s/he has any questions or concerns regarding the Informed Consent document, or regarding the research itself.

- If the potential participant agrees to participate in this study, ensure TWO copies of the Consent form are signed and dated. One copy will remain with the participant, one copy is to be returned to the Principle Investigator. The Research Assistant may act as witness. Ensure names, signatures, and dates are correct and complete.

The Interview:

- All interviews are to be conducted face-to-face, at a time that is mutually agreeable to both Research Assistant and participant.

- Remind participant of: a) study objectives; b) participant's right to answer as many or as few questions as s/he desires; c) participant's right to withdraw from the study at any time without consequence; d) role of audio-taping, field notes, and transcripts in this study; e) his/her right to request copies of individual (personal) transcripts and any reports or research papers that flow from this research.

- Indicate to participant that interview will take approximately 45 minutes. Ensure participant is comfortable, able to commit this time in a concentrated, uninterrupted manner, and is able to begin the interview.

- Ensure tape recorder is functional, audio level is appropriate, and that acoustic confidentiality is in place prior to commencing interview.

- Do not identify the participant's name during the interview, to protect his/her confidentiality.

- At the conclusion of the interview, thank the participant for his/her participation in this research project.

- Provide all audio files/tapes, field notes, confidentiality agreements, and other written documents to the Principal Investigator. 
JRIPE

17

Harmonious

Healthcare Teams

Whitehead, Whitehead, McLaughlin, \& Austin

Journal of Research in Interprofessional Practice and Education

Vol. 4.1

June, 2014

\section{Journal of Research in Interprofessional Practice and Education}

Semi-structured interview protocol:

Q1. Can you tell me about your background as a musician? Where did you go to school? How did you learn to be a musician?

Q2. Can you tell me about your experience with ensembles? What kind of ensembles have you performed with?

Q3. Could you describe your experiences when you have been a founding member of an ensemble? Could you describe your experiences when you have joined an ensemble that has already been functioning for a period of time? How are these experiences similar and different?

Q4. Think of the most effective and rewarding ensemble experiences you have had. What did the members of that ensemble do to make the experience so rewarding? How did they communicate with each other? How did they sort out disagreements or conflict?

Q5. Now, think of the least effective and least rewarding ensemble experience you have had. What did the members of that ensemble do? How did they communicate with each other? How did they sort out disagreements or conflict?

Q6. In your experience, what defines a high-functioning musical ensemble? What do ensemble musicians do to make an ensemble work very effectively?

Q7. How do you know when an ensemble is not functioning effectively? What strategies have you used in the past to deal with this? How successful were they?

Q8. How do ensembles, in your experience, work out who is going to be the leader if leadership is necessary? Do you have any experiences with ensembles that are truly leader-less? In some cases, some musicians may perpetually play a "supporting" role in an ensemble (for example, a continuo player). Is this, in your experience, an issue? How is it managed?

Q9. As you are aware, the purpose of this study is to examine the formation and functioning of musical ensembles to identify what lessons healthcare teams might learn about collaboration. Based on your reflections today, what suggestions would you have for healthcare professionals who may not be accustomed to working together in the same way an ensemble does?

Q10. Do you have any other questions or comments about this interview? Anything else you'd like to add?

Thank you for your participation in this research project. 